\title{
Baseline Scenario of Carbon Footprint of Polyester T-Shirt
}

\author{
Shadia Moazzem ${ }^{\mathrm{a}}$, Enda Crossin ${ }^{\mathrm{b}, \mathrm{c}}$, Fugen Daver ${ }^{\mathrm{b}}$, Lijing Wang ${ }^{\mathrm{a}, *}$ \\ a School of Fashion and Textiles, RMIT University, 25 Dawson St, Melbourne, VIC-3056, Australia \\ ${ }^{\mathrm{b}}$ School of Engineering, RMIT University, Plenty Road, Bundoora, Victoria 3083, Australia \\ ${ }^{\mathrm{c}}$ Faculty of Science, Engineering and Technology, Swinburne University of Technology, John Road, \\ Hawthorn, Victoria 3122, Australia
}

\begin{abstract}
Environmental sustainability is a vital issue in the clothing industry due to a large percentage of greenhouse gas (GHG) emissions from clothing manufacturing to consumption. The main GHGs are carbon dioxide $\left(\mathrm{CO}_{2}\right)$, methane $\left(\mathrm{CH}_{4}\right)$, nitrous oxide $\left(\mathrm{N}_{2} \mathrm{O}\right)$, hydro fluorocarbons (HFCs), per fluorocarbons (PFCs) and sulphur hexafluoride $\left(\mathrm{SF}_{6}\right)$. Carbon dioxide is considered as the most significant greenhouse gas. The carbon footprint (CFP) of clothing supply chain reflects the GHG emissions throughout the life cycle of a product or activity, and CFP assessment is an important approach to assess GHG emissions. Polyester is one of the most widely used synthetic fibres in the world, but it is produced from non-renewable resources. In this study, a life cycle assessment (LCA) of a polyester T-shirt imported to Australia from China has been undertaken to examine the processes which cause GHG emissions across the life cycle. The results of the baseline model showed that consumer use phase contributes the highest CFP $30.35 \%$, and second highest contributor is polyester fibre production process. Within the production phase, spinning is the highest contributor of CFP due to high electric energy demand. Within the consumer use phase, CFP is dominated by the washing process. The results of the model can be considered reliable comparing with other related studies.
\end{abstract}

Keywords: Sustainability; Greenhouse Gas Emission; Carbon Footprint; Life Cycle Assessment

\section{Introduction}

Environmental sustainability is a vital issue in the textile and clothing industry because buyers are more concerned about the sustainability of their clothing products, especially when purchasing imported apparel. Now the fashion industry is willing to develop their policies for sustainable environmental practice by giving attention to the carbon footprint (CFP) and energy used in the whole supply chain [1]. Sustainability can be maintained by several ways such as reducing energy consumption, improving productivity, reducing waste generation, recycling waste and using less

\footnotetext{
${ }^{*}$ Corresponding author.

Email address: lijing.wang@rmit.edu.au (Lijing Wang).
} 
material in production. According to North American magazine, Textile World, North Americans are the largest consumer of new textile products and Australians are the second largest consumer of new textile products based on average use per person [2]. Each Australian buys an average of $27 \mathrm{~kg}$ new textile product annually and after a certain time they dispose of $23 \mathrm{~kg}$ of the textile products. It is assumed that remaining $4 \mathrm{~kg}$ textile products are stored for reuse in their wardrobe. Each North American consumer buys $37 \mathrm{~kg}$ and each Western European consumer buys $22 \mathrm{~kg}$ textile products annually. Textile and clothing consumption rate in Africa, Middle East and India is about $5 \mathrm{~kg}$ per capita (Fig. 1) [2].

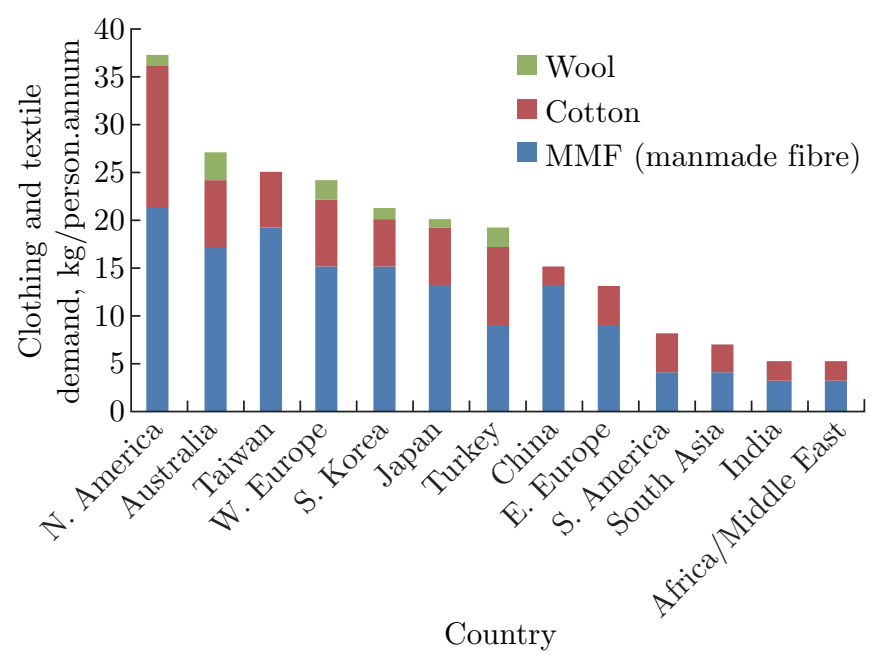

Fig. 1: Global consumer demand for clothing and textile, kg per person, per annum [2]

In 1980, 2000 and 2014, global polyester demand was 5.2, 19.2 and 46.1 million tonnes, respectively [2]. According to a study by Lenzing group on global fibre market in 2016, manmade fibres of synthetic origin (oil based synthetic fibre) occupied $62.7 \%$ and cellulosic and proteinbased natural fibre occupied $24.3 \%$ share of the global fibre market [3]. Polyester is the main manmade fibre of synthetic origin then followed by nylon and acrylic [4]. Therefore, the demand for polyester fibre is growing. According to the Textile World report dated on February 3, 2015, a large part (approximately 69\%) of global polyester is produced in China [2]. Textile World also stated that most of the new textile and clothing purchased by Australians are derived from manmade fibres [2].

Life cycle assessment (LCA) is a technique to access the environmental sustainability of a product or process. It involves the environmental impacts associated with the product or process, raw material acquisition, energy, resources, waste, and emissions to air, water and soil, etc. The main aim of this study is to assess the carbon footprint (CFP) throughout the life cycle of a basic polyester apparel item imported in Australia. This was done by developing a model of supply chain of the selected apparel from raw material extraction to use stage and end of life stage in Australia. A generic polyester knit T-shirt has been chosen as a basic apparel item. System boundary of this study is fibre production to disposal. Production stages include fibre production, yarn spinning, knitting, wet processing and apparel manufacturing. Consumer stages include apparel washing and drying behaviour of the purchased apparel. The carbon footprint (CFP) assessment of apparel supply chain helps to evaluate the basic conditions associated with the emission of greenhouse gas (GHG) during their production and use stages [5]. 


\section{Carbon Footprint of Textile Products}

Most of the studies on CFP of a textile product investigated life cycle assessment of the product supply chain which includes raw fibre production, yarn production, fabric production, apparel production, end use and disposal [1]. Textile fibres consist of two types, natural fibres and manmade fibres. Natural fibres have two sub groups, plant or vegetable fibres and animal fibres. For example, cotton, hemp, linen, jute and sisal are plant fibres and wool, silk, cashmere and angora are animal fibres. Manmade fibres are constituted of three categories, regenerated cellulosic fibre, synthetic fibre and inorganic fibre [1]. Manmade fibres of regenerated cellulose fibre origin, for example, viscose rayon, acetate rayon, lyocell, and modal, are produced from the transformation of natural polymers. Manmade fibres of synthetic origin, for example polyester, polyamide (nylon 6, nylon 66), polyolefin, and polyurethane, are produced from crude oil. The production process of manmade fibres of synthetic origin starts from crude oil production, followed by the production of polymer chips and then fibre. Manmade fibres of inorganic origin are produced from glass, metal, carbon or ceramic, for example, glass fibre, and ceramic fibre [1].

Production processes of different fibres produce different levels of GHG emissions depending on the individual production process, raw materials and energy used. Geographical location of fibre production is also another factor of varying GHG emissions. For example, cotton and polyester fibre production in different geographical location generates different levels of GHG emissions [1]. These differences are due to the different geographical location, technological efficiency of production process, electricity production and different sources of energy [1]. Several life cycle assessment studies have been carried out on different fibres to identify the GHG emissions from cradle to gate or cradle to grave stages [1]. A study conducted in the UK on the consumption of different types of fibres used in the UK clothing reported the CFP of different fibres as shown in Table 1. It can be stated from Table 1 that wool is the highest contributor of GHGs among other fibres due to the methane and nitrous oxide emission from sheep livestock $[1,6]$. Flax fibre is the smallest contributor to GHGs due to the low irrigation and pesticides used during fibre production [1].

Table 1: Greenhouse gas emissions during textile fibre production $[1,6]$

\begin{tabular}{cc}
\hline Fibre & Greenhouse gas emissions ( $\mathrm{kg} \mathrm{CO}_{2}$-eq per tonne of fibre) \\
\hline Nylon & 8070 \\
Viscose & 2118 \\
Acrylic & 7577 \\
Polyester & 5357 \\
Silk & 2031 \\
Cotton & 1755 \\
Wool & 20790 \\
Flax & 335 \\
Polypropylene & 3097 \\
\hline
\end{tabular}

The clothing supply chain involved many manufacturing processes from the production of raw materials to the finished product. Generally, these processes include fibre production and spinning, fabric engineering (weaving/knitting), wet treatments and product finishing. All of these processes require energy and other resources which directly and indirectly contribute to the GHG 
emissions [1]. A whole life cycle study conducted on a long-sleeve white cotton shirt (weight of 0.2 $\mathrm{kg}$ ) produced in Bangladesh using cotton from the US and finally consumed in Germany indicated that it emitted $10.75 \mathrm{~kg} \mathrm{CO}$-eq in its life time which are more than 50 times of the shirt weight. Around 28\% (3 $\mathrm{kg} \mathrm{CO} \mathrm{CO}_{2}$-eq) of these emissions arose from manufacturing processes, $31 \%$ (3.30 $\mathrm{kg} \mathrm{CO}_{2}$-eq) from use phase, $2 \%$ (0.25 $\mathrm{kg} \mathrm{CO}_{2}$-eq) from disposal phase, $12 \%\left(1.27 \mathrm{~kg} \mathrm{CO}_{2}\right.$-eq) from cotton cultivation phase and remaining $27 \%$ from packaging, transportation, retailing and distribution phase.

Consumer use phase of textile products is one of the most important contributors of CFP throughout the life cycle. The carbon footprint of the use phase depends on washing and drying machine efficiency, washing temperature, washing frequency, drying frequency over the life time of clothing [1]. Therefore, clothing care and maintenance can affect the CFP during the use phase [1]. Different types of garments have specific washing, drying and ironing requirements based on fibre type [6]. Hence, the level of GHG emissions from different types of garments made from different fibres varies. After the clothing being used for a certain time, there are several options for disposal such as reuse, recycling, incineration and landfill. Greenhouse gas emissions from the end of life scenario depend on the disposal options.

\subsection{Methodology}

Life cycle assessment is a technique to identify the potential environmental impact of any product or process using a systematic set of procedures: defining the goal of life cycle assessment study, compiling inputs and outputs of materials and energy associated with the product or processes, evaluating the potential environmental impacts from these inventory inputs and outputs throughout its life cycle, and interpreting the result of potential environmental impacts in relation to the goal of study [7]. Specific procedures and standards are followed to assess the environmental impact of product or process through LCA. The ISO14040:2006 was used in this LCA. This specific standard includes goal and scope, functional unit, system boundary, inventory analysis, impact assessment and interpretation [1]. The first step of LCA is to determine the goal. The goal of this study is to assess the CFP of a basic polyester T-shirt imported to Australia through LCA using secondary data available in the literature. The life cycle stages of any textile product include raw materials production/cultivation, yarn production, fabric production, transport, use and disposal. Fig. 2 shows the system boundary of this study which includes fibre production to disposal. A standard functional unit was chosen to calculate the materials throughout the system boundary. Then energy and emissions of each individual sub-process were calculated on the basis of the functional unit, which is ' 50 days use of polyester knitted T-shirt over one year life time'. It was assumed that the T-shirt was washed after each wearing. The weight of T-shirt was $0.18 \mathrm{~kg}$ [8]. Two types of data, activity data and emission factor data, are required to calculate the CFP of a textile product. Activity data involves the amount of all input and output materials, transportation, use phase and energy. Emission factor data refers to the link between activity data and emission data that converts the amount to GHG emission. Activity data and energy/emission factor data can be collected from primary and secondary sources. In this study, literature sources were used for data collection. Energy requirements of each individual process were determined according to the fuel consumption and reported electricity inputs. The CFP of each sub process of the supply chain was calculated from the input of materials, input of energy and $\mathrm{CO}_{2}$-eq conversion factor for energy. The specific equation used to calculate the $\mathrm{CFP}$ of each 
sub process is shown in Equation (1).

$$
C F P_{m}\left(\operatorname{kg} \mathrm{CO}_{2-\mathrm{eq}}\right)=\left[\{M+(M \operatorname{loss} \%)\} E_{m}\right] W_{m}
$$

where $C_{F P}$ is the carbon footprint of material $M$ from the individual process; $M$ is material input; $E_{m}$ is energy conversion factor for the material; $W_{m}$ is the CFP conversion factor for energy.

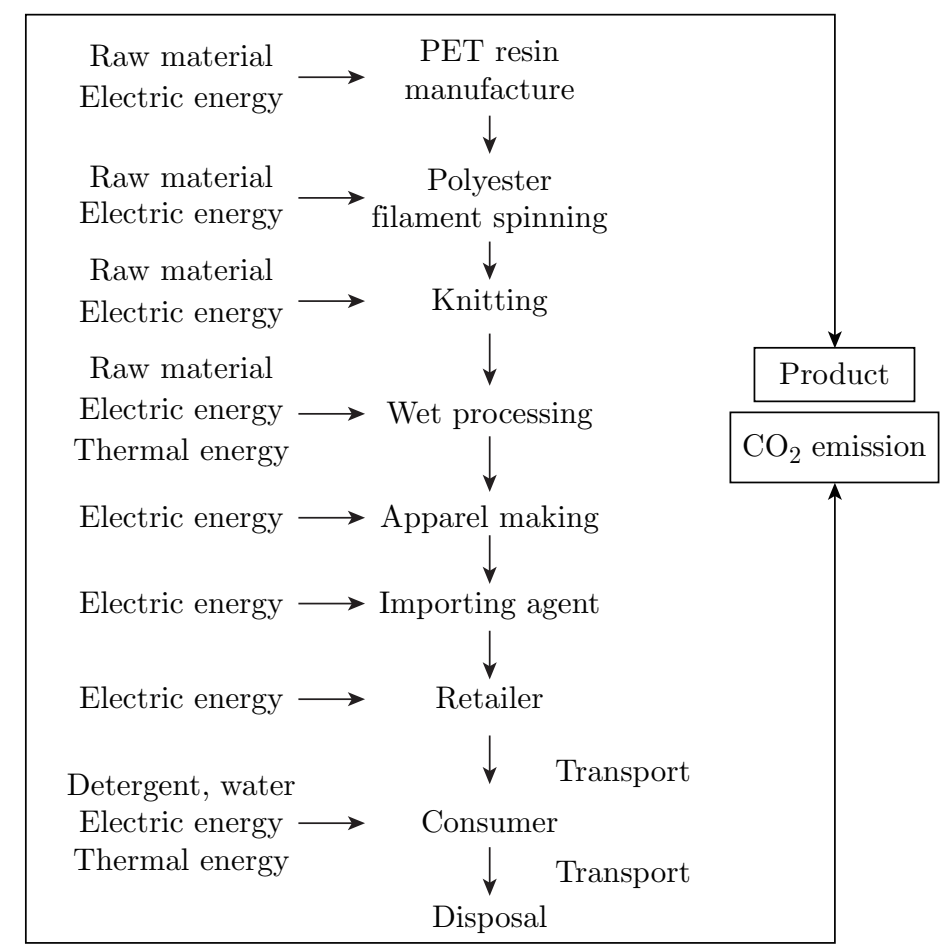

Fig. 2: Life cycle assessment system boundary

Transportation energy was calculated through estimating transport distances and transport modes for the whole supply chain. Transport mode was considered a combination of several means of transports such as truck, ship and car. Rail transport was not considered for transport stage. Conversion factors were used to determine transport fuel energy and $\mathrm{CO}_{2}$-eq emission. Equation (2) illustrates the CFP from transport.

$$
C F P_{t}\left(\operatorname{kg} \mathrm{CO}_{2-\mathrm{eq}}\right)=M_{m t} D_{t} E_{t} W
$$

where $C F P_{t}$ is the CFP of material $M$ from transport; $M_{m t}$ is the mass of material transported; $D_{t}$ is travel distance; $E_{t}$ is the mass of transport fuel; $W$ is the CFP conversion factor for fuel. The carbon footprint of knitting $\left(C F P_{\text {knitting }}\right)$ sub process for one functional unit was estimated using Equation (3):

$$
C F P_{\text {knitting }}=[\{204.79+(204.79 * 1.5 \%)\} / 1000] * 8.08 * 0.8529=1.4 \mathrm{~kg} \mathrm{CO}_{2-\mathrm{eq}}
$$

\subsection{Raw material extraction and production phase}

The main raw materials for polyester yarn production are PET chips, spin finish oil, the antimicrobial agent, caustic soda, sodium hydrosulphite, acetic acid (98\% Glacial) and retarding agent 
[9]. Electrical energy is used to operate all of the machines involved in spinning, air conditioning and illumination and compressors. Thermal energy is used for air conditioning and treatment processes [10]. About 78\% of energy is required to operate all machines, $3 \%$ for lighting, $3 \%$ for compressors and $16 \%$ for air conditioning and humidification [1]. According to a study performed by Collins and Aumônier [11], the total energy consumption of spinning process is $22.23 \mathrm{kWh} / \mathrm{kg}$ and this estimation was based on British Textile Technology Group.

For this study, it is assumed that the loss of spinning process and fibre preparation process was $15 \%$ and $5 \%$, respectively. The environmental impact from fabric manufacturing depends on the fabric engineering process, namely knitting and weaving. Knitting is a comparatively simple process and produces less emission as it uses only single machine to convert yarn to fabrics, whereas weaving involves several pre-processes that consume more energy and produce more emissions to the environment. In this study it was assumed that the knitted T-shirt fabric is polyester single jersey fabric. Energy consumption was assumed to be $8.08 \mathrm{kWh} / \mathrm{kg}$ and yarn loss during knitting was 1.5\% [11]. Pre-treatment, dyeing and finishing processes are involved in wet processing. All of the pre-processes of wet processing are usually carried out on the same machine. Dyeing process of knitted fabrics is carried out using a jet or winch dyeing machine. In this study, it was assumed 3\% fabric loss during dyeing and pre-treatment, and energy consumption for dyeing and finishing process was considered $7.11 \mathrm{kWh} / \mathrm{kg}$ [11].

Apparel manufacturing process involves design, laying, cutting, pattern making, sewing, ironing and finishing. According to a recent study [12], the apparel production process has the relatively low impact on the environment among other sub processes. In this study, it was assumed $11 \%$ material loss during the inspection, laying, cutting and sewing, and $2.38 \mathrm{kWh} / \mathrm{kg}$ energy consumption. Energy requirement in each production stage was based on studies by Collins \& Aumônier [11] where energy refers to the process energy and raw material extraction energy, which includes electricity and fuel used by machines and products. The energy data were based on medium voltage electricity supply [11]. Electric power for Zhejiang province and Hubei province are supplied from China east power grid and central grid respectively. A carbon emission factor for electricity consumption was calculated based on the carbon emission factor of central power grids in China which is $0.8529 \mathrm{~kg} \mathrm{CO}$-eq/KWh [12]. A carbon emission factor, 77 tonnes $\mathrm{CO}_{2}$-eq/TJ (0.25 $\mathrm{kg} / \mathrm{kWh}$ ) for fuel oil, was considered based on the Intergovernmental Panel on Climate Change IPCC [12]. The carbon footprint of consumer stage and end of life stage was calculated based on the average emission factor of purchased electricity from the power grid of different states and territories in Australia. The average emission factor was $0.69 \mathrm{~kg} \mathrm{CO}_{2}$-eq/kWh [13].

\subsection{Transportation phase}

In this study, it was assumed that the whole manufacturing process (from raw materials to apparel production) of the polyester T-shirt took place in Shanghai, China and then the shirt was shipped to Melbourne, Australia. Transportation energy was calculated by estimating the transport distances and transport modes for the whole supply chain. Transport fuel energy content was calculated based on the fuel required for each transport mode [14]. Travel distance was calculated based on the calculator of sea-distances.org [15]. Standard conversion factors were used to calculate the $\mathrm{CO}_{2}$ emission from each transport mode [14]. 


\subsection{Product use and customer care}

The use phase of any apparel starts from the purchase of apparel by the consumer and it is controlled by consumer choice. It includes frequency of washing, washing temperature, washing machine load, choice of cloth drying method, use of iron and selection of washing machine and dryer. Environmental impact from this phase depends on these factors.

\subsubsection{Washing}

It can be assumed that the proportion of household clothing wash in Australia by hand is very small [16]. Therefore, 100\% machine washing was considered for this study. According to a survey by Canstar blue (A consumer survey company in Australia), 35\% Australians consider purchasing a front loader washing machine while $75 \%$ Australians consider purchasing top loader washing machine and Fisher \& Paykel brand washing machine is in the top rank for top loader washing machine [17]. Though according to the survey most of the Australians use top loader washing machines, front loader washing machine causes less emissions as it consumes less energy and around $50 \%$ less water than top loader washing machine [18]. The maximum energy rating of a washing machine is five stars and the minimum is one star. The more stars means the machine is more energy-efficient. In this life cycle assessment study, the average energy star two for energy and water use efficiency was considered. The capacity of the household washing machine used in Australia ranging between $3 \mathrm{~kg}$ to $10 \mathrm{~kg}$ [17]. The capacity of the machine is an important fact as a small machine will add extra wash cycle, energy and water bill. The most common washing machine capacity used in Australia is $6 \mathrm{~kg}$ considering the family size [16]. Most washing machines have three options for washing, cold wash (around $26{ }^{\circ} \mathrm{C}$ ), warm wash (around $32{ }^{\circ} \mathrm{C}$ ), and hot wash (around $54^{\circ} \mathrm{C}$ ) [19]. According to Australian Bureau of Statistics (ABS), 80\% Australians use cold water to wash their clothing, therefore, 20\% Australians were assumed using warm water to wash their clothing [16]. Only $26 \%$ of Australians use full load washing machine and it is assumed that the rest $74 \%$ of the population use washing machine with half load [16]. The same pattern of machine load was assumed for $20 \%$ Australians who use warm water and $80 \%$ Australians who use cold water in their washing machine. For simplification of this study, the use of hot water in the washing machine for polyester T-shirts is assumed to be very rare and negligible. Machine load is an important factor for energy and water use. Impact $\%$ of one garment for the full load and half load machine wash was calculated using Equation (4):

Impact \% per garment (based on machine load $)=\left(100^{*}\right.$ garment weight $) /$ machine load

Using Equation (4), washing one T-shirt (0.18 kg) with full machine load $(6 \mathrm{~kg})$ will account for $3 \%\left[0.18 / 6^{*} 100\right]$ impact, which means the washing machine uses $3 \%$ of the total washing energy for one T-shirt. Washing of one T-shirt with half machine load ( $3 \mathrm{~kg})$ will account for $6 \%\left[0.18 / 3^{*} 100\right]$ impact, which means washing machines uses $6 \%$ of the total washing energy for one T-shirt. Data from the Australian government website www.data.gov.au indicated that Fisher \& Paykel brand two stars top loader washing machine consumes $57 \mathrm{kWh}$ for 365 times cold washing and $505 \mathrm{kWh}$ for 365 times warm washing [20]. Therefore, energy consumption 0.156 $\mathrm{kWh} /$ cold wash and $1.384 \mathrm{kWh} /$ warm wash were estimated based on this data for two star top loader washing machines. Equations (5), (6), (7) and (8) were used to calculate the energy of 
washing machine.

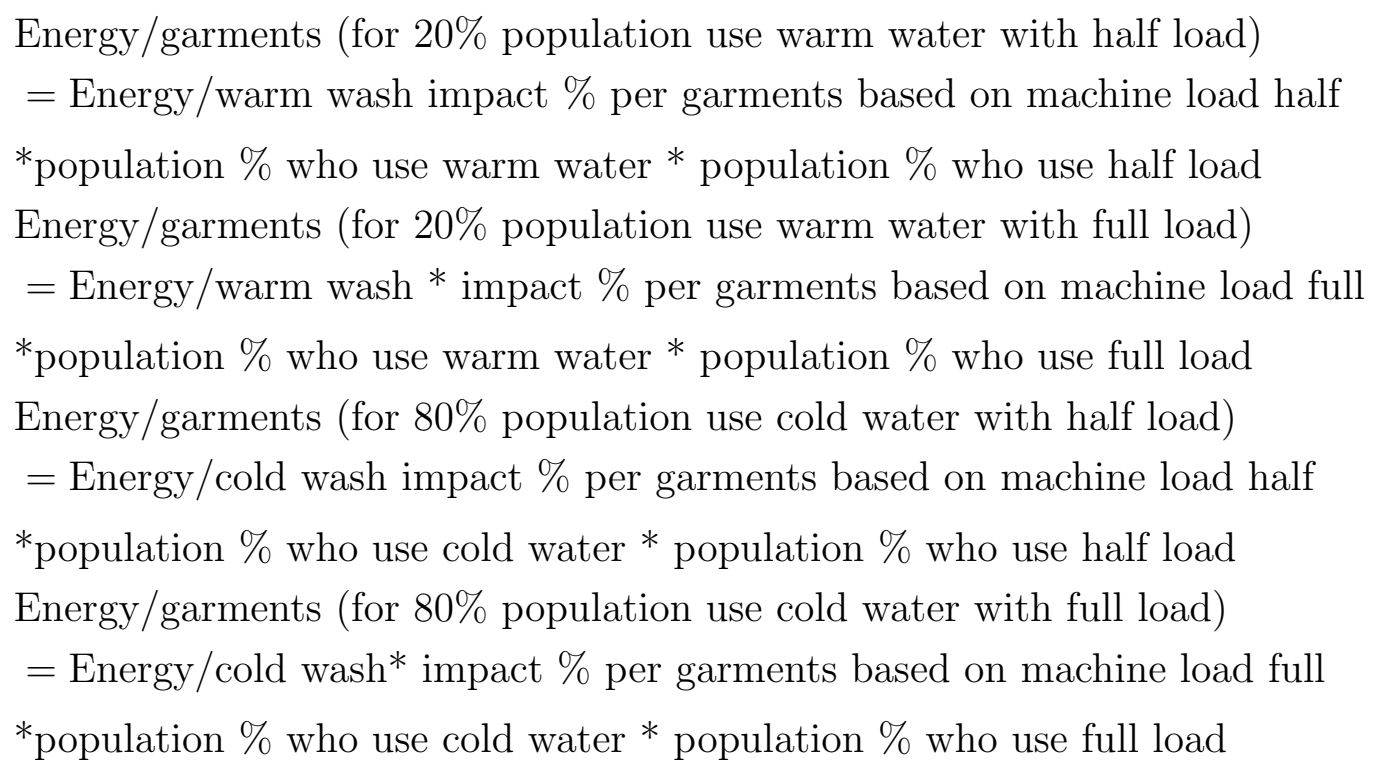

The total energy required for the washing machine was estimated $0.0623 \mathrm{kWh}$ for one T-shirt for one wash. It was assumed that the T-shirt was washed 50 times in its lifetime, therefore, the total energy required for lifetime washing was calculated as $3.11 \mathrm{kWh}$ from the multiplication of energy required for one wash and a total number of washes. The carbon footprint of the washing machine was calculated based on the average emission factor of $0.69 \mathrm{~kg} \mathrm{CO}_{2}$-eq/ $\mathrm{kWh}$ (average emission factor for states and Territory in Australia) of purchased electricity from the grid of different states and Territory in Australia [13]. The two-star Fisher and Paykel brand washing machine consumes approximately 98 litres water for cold wash and 82 litres for warm wash [21]. For the purpose of this study, it was assumed that 90 litres water is required per wash for $6 \mathrm{~kg}$ machine load. Therefore, 2.7 litres water was estimated for one T-shirt for one wash, and accordingly, 135 litre water was estimated for its life time. After washing, the wash water is discharged to the sewer. Depending on the country, this wastewater is treated through primary treatment and or secondary treatment and then treated by tertiary treatment through sand filtration, nutrient removal, etc. Sometimes the waste water is discharged directly to the environment without any treatment process [22]. It is assumed that $0.001 \mathrm{kWh}$ of electricity is required for one litre of water supply, treatment and pumping based on life cycle assessment studies of Marks and Spencer apparel. This energy includes waste water and clean water supply and pumping [11]. Hence, $0.135 \mathrm{kWh}$ electricity was estimated at 135 litres water supply. $\mathrm{CO}_{2}$ emission from water supply was calculated based on the GHG emissions from water related energy demand in Australia [23]. In this study one scoop of detergents, which equates to $15 \mathrm{~g}$, is required per wash for $6 \mathrm{~kg}$ washing machine load [11]. Therefore, $0.75 \mathrm{~kg}$ detergent will be required in the life time to wash one T-shirt. Detergent extraction energy and emission factor for detergent production were calculated based on literature data [11,12]. Detergent extraction energy (total $6.94 \mathrm{kWh}$ ) was calculated based on the extraction energy of standard powder [11]. For emission factors of detergent production, chemical products manufacturing subsectors emission factors of China [12] were considered. Therefore, $2.5 \mathrm{~kg} \mathrm{CO}$ was calculated for detergent production from the multiplication of extracted energy and emission factor. 


\subsubsection{Drying}

According to the ABS data, in 2005, 55\% of households in Australia had the tumble dryer. This percentage is just 3\% increase over the time since 1992 [16]. The increase rate of the ownership of household tumble dryer is very minimum and insignificant over the time. Therefore, $55 \%$ dryer owner was considered for this study. The rest $45 \%$ population use line dry to dry their cloth and the environmental impact can be considered to zero. Use behaviour (frequency of use) of the dryer of $55 \%$ household tumble dryer owner is varying depending on summer and winter season as shown below [16].

In summer: $39 \%$ population use dryer very rarely

In summer: $16 \%$ population use frequently

In winter: $23 \%$ population use rarely

In winter: $32 \%$ population use frequently

For simplification of this base model, on average $31 \%$ (average of summer and winter population) population use dryer rarely in both seasons (assumed that rarely means they use tumble dryer $10 \%$ in both seasons) and $24 \%$ (average of summer and winter population) population use dryer frequently in both seasons (assumed that frequently means they use tumble dryer $90 \%$ in both seasons). From the average data, 45\% (100-31-24) population use dryer moderately in both seasons, which means that they use dryer $50 \%$ in both seasons. Equations (9), (10) and (11) were used to estimate the fabric weight for drying.

Actual weight of garments to dry frequently

$=$ garments actual weight $*$ population $\%$ of dryer owner

* population $\%$ who use dryer frequently

* population $\%$ of actual dryer use among frequently use $\%$

Actual weight of garments to dry frequently

$=$ garments actual weight ${ }^{*}$ population $\%$ of dryer owner

* population $\%$ who use dryer rarely

* population \% of actual dryer use among rarely use \%

Actual weight of garments to dry moderately

$=$ garments actual weight ${ }^{*}$ population $\%$ of dryer owner

* population $\%$ who use dryer moderately

* population $\%$ of actual dryer use among moderately use $\%$

The capacity of the household tumble dryer is measured by weight between $5 \mathrm{~kg}$ to $8 \mathrm{~kg}$. Tumble dryer load capacity is influenced by the average household sizes [17], which is about 4 people in Australian. Hence, the average capacity of the household dryer is $6 \mathrm{~kg}$ in Australia [16]. Impact percentage of cloth drying was calculated based on the average capacity of the dryer using Equation (12). There is no data available on population percentage of use tumble dryer full load and half load. Therefore, full load dryer was considered for this study. The drying impact is $3 \%$ per one garment for full load machine dry, which means a drying machine uses $3 \%$ of the total drying energy for one T-shirt. The required energy for a dryer was calculated based on the 
average energy of two mostly used dryer in Australia as shown in Table 2 [21].

Impact \% per garments (based on machine load) $=100 *$ garments weight $/$ machine load (12)

Table 2: Average energy use for drying [21]

\begin{tabular}{cccc}
\hline Dryer Brand & Capacity & Energy & Energy/use \\
\hline Fisher \& Paykel & $6 \mathrm{~kg}$ & $267 \mathrm{kWh} / 52$ uses & $5.1 \mathrm{kWh}$ \\
Samsung electronics & $6 \mathrm{~kg}$ & $290 \mathrm{kWh} / 52$ uses & $5.57 \mathrm{kWh}$ \\
& & & Average $5.33 \mathrm{kWh}$ \\
\hline
\end{tabular}

Total drying energy, $0.0074 \mathrm{kWh}$ for one dry has been estimated from Equation (13). Therefore, the total drying energy of the life time is $0.37 \mathrm{kWh}$. Emission factor of purchased electricity from the grid of Australia was used to estimate the CFP of cloth drying [13], which was about $0.26 \mathrm{~kg}$ $\mathrm{CO}_{2}$-eq of its life time.

Energy per garments to dry = impact \% per garments

* energy per drying cycle * actual weight of garments to dry/100

Ironing is not necessary for polyester T-shirt. Therefore, no GHG emission was considered from ironing in the use stage. The carbon footprint of consumer use stage is shown in Table 3.

Table 3: Carbon footprint of GHG emissions of consumer use stage ( $\mathrm{kgCO}_{2}$-eq per functional unit)

\begin{tabular}{cc}
\hline & Carbon footprint of $\mathrm{GHG}$ emission $\left(\mathrm{kg} \mathrm{CO}_{2}\right.$-eq) \\
\hline Water supply, treatment and pumping & 1.34 \\
Washing machine & 2.15 \\
Detergent & 2.5 \\
Drying machine & 0.26 \\
Total & 6.25 \\
\hline
\end{tabular}

\subsection{End of Life Scenario in Australia}

End of life of any textile product depends on the consumer choice. A fibre product can be reused, recycled, incinerated or dumped in landfill [1]. According to ABS, 500,000 tonnes of leather and textiles were disposed of each year in Australia but only a small fraction of the disposal items were sent for recycling. Around $85 \%$ of the waste leather and textiles were disposed of through landfill and only 18\% were recovered by recycling and reuse [24]. In Australia, used clothing is mainly collected by charities and clothing recyclers. Over 50 million kilograms of textile waste were collected through charity bins by different charity organisations and clothing recyclers in Australia. About 12.5 million kilograms of the collected textile waste were unsuitable for recycling and reuse, which were sent to landfill. The rest of the collected clothing waste was recovered by recycling and reusing through charity shops and recycling organisations [25]. 
Thousands of charity bins for the collection of used clothing are located in every state in Australia to collect the used clothing. The collected second-hand clothing was sorted and graded according to the quality and fibre type, then sent to different destinations such as reuse, recycling or to another country. Charity shops are the main way to resale second-hand clothing. Australia has a big international market for used textiles. According to a discussion paper [25], approximately 50,000 tonne worn clothing and textiles were exported annually to 44 countries from Australia under two tariff codes 63090010 (worn clothing) and 63090090 (worn textile articles) [25]. In 2012 Australia exported 70,000 tonnes of second-hand clothing which values over $\$ 70$ million.

For the baseline scenario, it was assumed that a polyester T-shirt would be discarded for reuse after one year through Salvation Army Trading Company (SATC). Based on a SATC report, collection, processing, and distribution of second-hand clothing consume $1.7 \mathrm{kWh}$ energy per $\mathrm{kg}$ clothing [11], which was adapted to calculate the total energy for reuse in this study. An average emission factor $(0.69 \mathrm{~kg} \mathrm{CO}$-eq/ $\mathrm{kWh})$ of purchased electricity from the power grid of different states and territories in Australia was used to calculate the CFP from the energy consumption during reuse [13].

\section{Results and Discussion}

The LCA results showed that the CFP of a polyester T-shirt is $20.56 \mathrm{~kg} \mathrm{CO}_{2}$-eq throughout its life cycle. The CFP contribution analysis of each life cycle process is shown in Fig. 3 and Fig. 4. Consumer use phase contributes the highest CFP, 30.35\%. The polyester fibre production process is the second highest CFP contributor, 28.94\%. Spinning is the highest contributing part of CFP in T-shirt manufacturing stage. Dyeing, finishing and pre-treatment stages are affected by the diverse range of chemicals and energy sources. The CFP of transportation stage depends on the transportation mode and travel distance. In this study, we assumed that all of the production stages occurred in the same place which reduced CFP from transportation stage. Transportation and disposal stage contributes CFP $4.33 \%$ and $1.03 \%$, respectively.

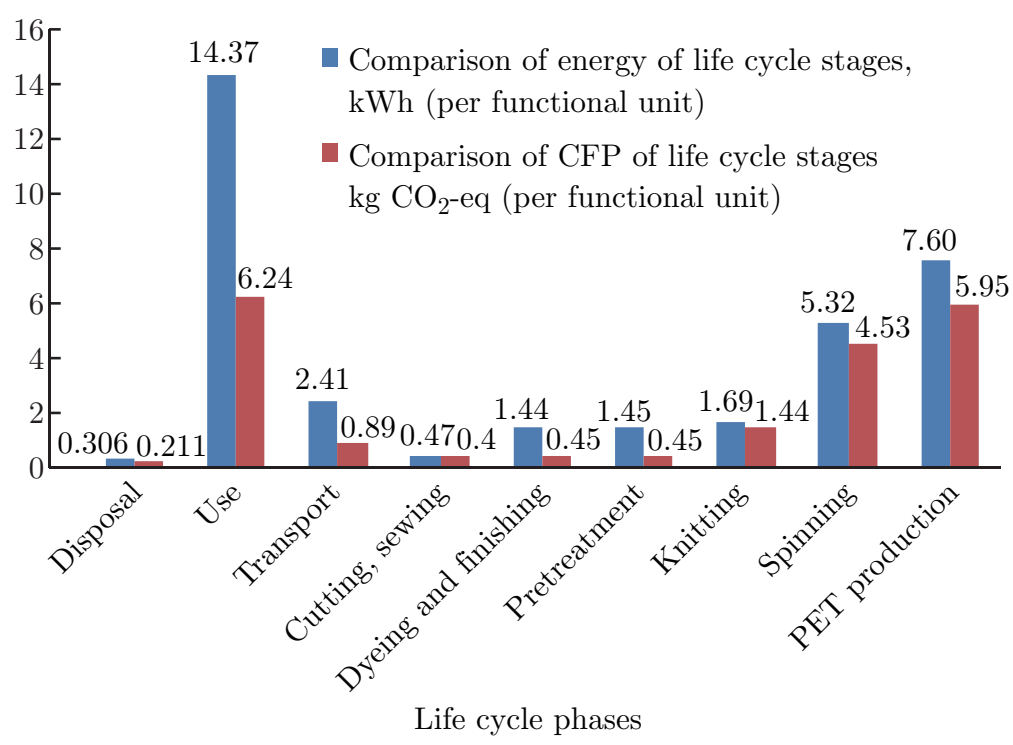

Fig. 3: Carbon footprint and energy consumption per functional unit at different life cycle phases 


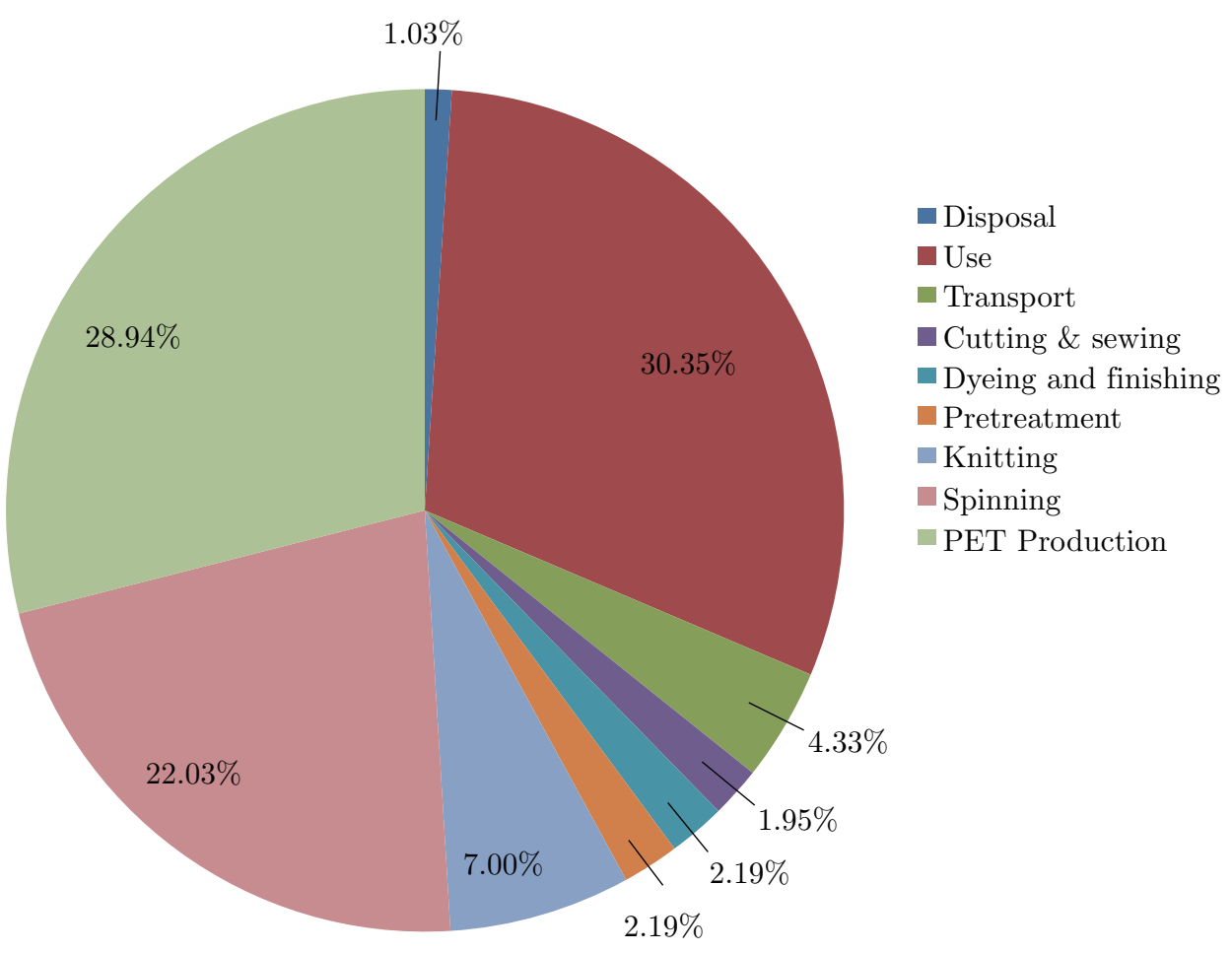

Fig. 4: Carbon footprint contribution (\%) analysis throughout the life cycle

The CFP of consumer stage completely depends on the consumer caring behaviour of their purchased clothing. Frequent washing with warm or hot water will result in high CFP. Washing machine load and machine selection according to energy rating also influence CFP. Most of the studies show that the use phase is the main CFP contributing phase due to the consumer washing frequency with warm water, which results in high energy use [1].

Users have a number of choices at the end of any apparel such as to discard, sell, or donate them to charity or municipalities. Depending on the quality, the donated textiles are sent to op-shops for reselling/recycling, or incineration plant. In this study, the T-shirt was assumed to be ended up through reuse which causing minimum CFP by avoiding the production phase.

At present, most of the studies of textile CFP mainly focus on the production process. In this study, the system boundary includes all of the stages of life cycle including sub production processes and apparel use and end of life stage in Australia. There are very few studies of polyester apparel life cycle, most of the LCA studies are based on cotton apparel. A comparatively recent study on a cotton shirt produced in China shows the CFP as $8.77 \mathrm{~kg} \mathrm{CO}_{2}$-eq throughout its life cycle [5], but this study did not mention the number of washes of its life time. Another LCA study on CFP of the white long-sleeve shirt shirt quantified $10.75 \mathrm{~kg} \mathrm{CO}_{2}$-eq of the lifetime and reported that the use phase contributed $31 \%$ of total $\mathrm{CO}_{2}$ emission [1]. Levi and Struss Co performed a LCA study on a pair of jeans which estimated $33.4 \mathrm{~kg} \mathrm{CO} \mathrm{CO}_{2}$-eq [26]. According to the Department for Environment, Food and Rural Affairs (DEFRA), in 2010, GHG emission from the production of polyester fibre is more than cotton [27]. A LCA study on polyester jacket produced in China quantified that $\mathrm{CFP}$ of the polyester jacket is $10.52 \mathrm{~kg} \mathrm{CO}_{2}$-eq in the total life time. This study considered total six times washes of the entire life time [1]. Consumers wash their T-shirt more frequently than jacket. The result of this study is thus comparatively high as 50 times wash was assumed over the life time. The result of this study can be considered more reliable comparing 
other LCA studies as mentioned in the literature.

\section{Conclusion and Recommendations}

This study has presented the baseline scenario of the carbon footprint of polyester T-shirt imported in Australia from China. In this study, the most industrial production sub-processes and other life cycle stages were included. Assessment data were collected from secondary sources due to the unavailability of primary sources. However, it is very difficult to collect more detailed information regarding production processes, input and output from previous studies. Because of this, only the specific information of the production processes was used in this study. Furthermore, the detailed information and data are necessary to complete carbon footprint modelling of any product. From this study, it can be concluded that the use stage contributes more carbon footprint among all the stages of polyester T-shirt life cycle. The next energy-intensive stages are polyester production and spinning process. Improving energy efficiency and implementing renewable energy sources in production stages can reduce the energy demand which ultimately will result in less carbon footprint and improved environmental performance.

The consumer has a great influence on carbon footprint reduction from use stage by changing their caring behaviour of purchased clothing. Washing with cold water results in less energy demand than washing with warm and hot water. As $80-90 \%$ of the energy used by the washing machine is for heating the water. Washing with cold water is an efficient way to save energy and reduce carbon footprint. Machine load is another important factor for energy and water use. Using full load machine can reduce energy and water demand. Other options for reducing environmental burden are increasing the life time by recycling and reuse which can reduce the demand for new products.

\section{References}

[1] Muthu SS. Handbook of sustainable apparel production. CRC Press, 2015.

[2] Information on http://www.textileworld.com/textile-world/fiber-world/2015/02/man-made-fiberscontinue-to-grow/

[3] Information on http://www.lenzing.com/en/investors/equity-story/global-fiber-market.html.

[4] Allwood JM, Laursen SE, de Rodriguez CM, Bocken NM. Well dressed. The present 2006.

[5] Wang C, Wang L, Liu X, Du C, Ding D, Jia J, Yan Y, Wu G. Carbon footprint of textile throughout its life cycle: A case study of Chinese cotton shirts. Journal of Cleaner Production 2015; 108: 464475 .

[6] Thomas B, Fishwick M, Joyce J, van Santen A. A carbon footprint for UK clothing and opportunities for savings: Banbury, UK: WRAP, 2012.

[7] Finkbeiner M, Tan R, Raimbault M. Life cycle assessment (ISO 14040/44) as basis for environmental declarations and carbon footprint of products. Paper presented at the ISO Technical Committee 207 Workshop, Norway, 2011.

[8] Information on http://www.jerzees.com/21MR.shtml.

[9] Information on http://www.ethioembassy.org.uk/trade_and_investment/Investment\%20Profiles\% 20EIA/Textile\%20Industry\%20Profiles/polyster\%20yarn.pd. 
[10] Koc E, Kaplan E. An investigation on energy consumption in yarn production with special reference to ring spinning. Fibres Text. East. Eur 2007; 15: 18-24.

[11] Collins M, Aumônier S. Streamlined life cycle assessment of two marks \& spencer plc apparel products. Environmental Resources Management, Oxford 2002.

[12] Lu H. China's industrial carbon dioxide emissions in manufacturing subsectors and in selected provinces. ECEEE Industrial Summer Study, Arnhem, the Netherlands, September 11-14, 2012, 2013.

[13] Information on https://www.environment.gov.au/system/files/resources/3ef30d52-d447-4911-b85c1ad53e55dc39/files/national-greenhouse-accounts-factors-august-2015.pdf.

[14] Information on https://www.patagonia.com/pdf/en_US/common_threads_whitepaper.pdf.

[15] Information on http://www.sea-distances.org.

[16] Grace P, Benchmarking and reducing greenhouse gas emissions and improving resource use efficiency: Queensland University of Technology, 2010.

[17] Information on http://www.canstarblue.com.au/appliances/laundry/top-loader-washingmachines/.

[18] Information on http://www.sustainability.vic.gov.au/services-and-advice/households/energyefficiency/at-home/appliances/washing-machines.

[19] Information on www.washlaundry.com/residents/laundry-tips/temperature/.

[20] Information on https://data.gov.au/dataset/energy-rating-for-household-appliances.

[21] Information on https://www.choice.com.au/compareall/home-and-living/laundry-and-cleaning/ washing-machines/washing-machines.

[22] Saouter E, Hoof Gv. A database for the life-cycle assessment of Procter \& Gamble laundry detergents. The International Journal of Life Cycle Assessment 2002; 7: 103-114.

[23] Kenway S, Priestley A, Cook S, Seo S, Inman M, Gregory A, Hall M. Energy use in the provision and consumption of urban water in australia and new zealand. Water Services Association of Australia (WSAA): Sydney, Australia 2008.

[24] Information on http://textilebeat.com/aussies-send-85-of-textiles-to-landfill/.

[25] Information on http://www.nacro.org.au/wp-content/uploads/2013/04/TEXTILE-WASTEPAPER-March-2009-final.pdf.

[26] Levi and Struss Co (2015). Life cycle assessment of a jean, 2016.

[27] Turley DE, Horne M, Blackburn RS, Stott E, Laybourn SR, Copeland JE, Harwood J, The role and business case for existing and emerging fibres in sustainable clothing: Final report to the department for environment, food and rural affairs. London, UK, 2009. 